\title{
Utilization of Foaming Technology in Cemented Paste Backfill of High-Mud Superfine Unclassified Tailings
}

\author{
Jian-wen Zhao, ${ }^{1}$ Xin-min Wang, ${ }^{1}$ Kang Peng, ${ }^{2}$ and Shuai Li ${ }^{1}$ \\ ${ }^{1}$ School of Resources and Safety Engineering, Central South University, Changsha 410083, China \\ ${ }^{2}$ State Key Laboratory of Coal Mine Disaster Dynamics and Control, College of Resources and Environmental Science, \\ Chongqing University, Chongqing 400030, China \\ Correspondence should be addressed to Shuai Li; 15200826420@163.com
}

Received 13 June 2017; Accepted 6 September 2017; Published 10 October 2017

Academic Editor: Marino Lavorgna

Copyright (c) 2017 Jian-wen Zhao et al. This is an open access article distributed under the Creative Commons Attribution License, which permits unrestricted use, distribution, and reproduction in any medium, provided the original work is properly cited.

\begin{abstract}
Due to high-mud content in superfine unclassified tailings (SUT), the viscosity of cemented paste backfill (CPB) is high and its pipeline transportation properties are poor. Foaming technology was introduced to prepare a new three-phase flow backfill (TFB) using a foaming machine. Then the rheological parameters of TFB with different bubble ratio were measured and their pipeline transportation properties were simulated by Fluent. Besides, the simulation results were further verified by a semi-industrial loop test. The results indicate that the optimum ratio of TFB is a cement-sand ratio of $1: 8$, mass concentration of $70 \%$, and bubble ratio of $20 \%$. Compared with CPB, the decrease of bleeding rate, viscosity, and resistance loss of TFB is $27 \%$, $25 \%$, and $30 \%$, respectively. Therefore, foaming technology is an innovative and feasible solution for high-mud CPB in reducing viscosity, decreasing resistance loss, and improving pipeline transporting efficiency.
\end{abstract}

\section{Introduction}

The cemented paste backfill (CPB) of superfine unclassified tailings (SUT) has many advantages such as a high tailings utilization ratio, effective prevention and control of surface subsidence, safety of mining operations, and lower mine loss and dilution and is being applied in mines more and more widely [1]. As for the largest underground iron mine in Asia, Sijiaying, a series of backfill and dry-stack experiments for the safe disposal of the 70 million tons/year tailings slurry output has been conducted. However, the tailings are abundant in argillaceous minerals such as biotite and chlorite, owing to the highly oxidized and argillized nature of low-grade ores [2]. As a result, the high-mud content in SUT, the high viscosity of $\mathrm{CPB}$, and its poor fluidity lead to its difficult pipeline transportation, restricting the application and promotion of CPB [3].

To solve these problems, researches are mainly focused on aspects of desliming and new modified material development $[4,5]$. Huang et al. [6] applied humic flocculant to the disposal of Bayer red mud based on selective flocculation desliming process. Cihangir et al. [7] tested alkali-activated neutral and acidic blast furnace slags as alternative binders to ordinary Portland cement for CPB of high-mud mill tailings. However, desliming remains difficult due to the high cost and complex process, while new modified materials show limited market application and insignificant effect during our tests.

Solid-liquid-gas three-phase flow backfill (TFB) is a new filling technology, which shows better flowing properties, easier implementation of gravity pipeline transportation, and higher filling quality. Tian et al. [8] conducted a series of field blast tests and found that foamed concrete can be used to attenuate blast load and reduce structural deformation effectively. Xu et al. [9] proposed a foam-cemented paste backfill with the use of ultrasonic pulse velocity measurements as a strength monitoring method in place of uniaxial compressive strength. But there are still many blank areas in the application research of TFB and only a few successful examples in mining application.

In this paper, foaming technology was introduced into the preparation of TFB in Sijiaying and Fluent simulation and semi-industrial loop test were conducted to explore its role in reducing the viscosity, improving the fluidity, and enhancing the pipeline transportation performance. 
TABLE 1: Grain diameter of SUT at Sijiaying.

\begin{tabular}{lccccccc}
\hline$D(\mathrm{~mm})$ & $5 \sim 2$ & $2 \sim 0.5$ & $0.5 \sim 0.25$ & $0.25 \sim 0.075$ & $0.075 \sim 0.05$ & $0.05 \sim 0.005$ & $<0.005$ \\
\hline Content $(\%)$ & 0.3 & 3.3 & 6.8 & 2.5 & 6.1 & 63 & 13 \\
\hline
\end{tabular}

TABle 2: Particle sizes of mud content in SUT.

\begin{tabular}{lccccc}
\hline$D(\mu \mathrm{m})$ & $D<6.5$ & $18>D>6.5$ & $26>D>18$ & $36>D>26$ & $D>36$ \\
\hline Content $(\%)$ & 71.20 & 15.15 & 5.20 & 3.05 & 5.40 \\
\hline
\end{tabular}

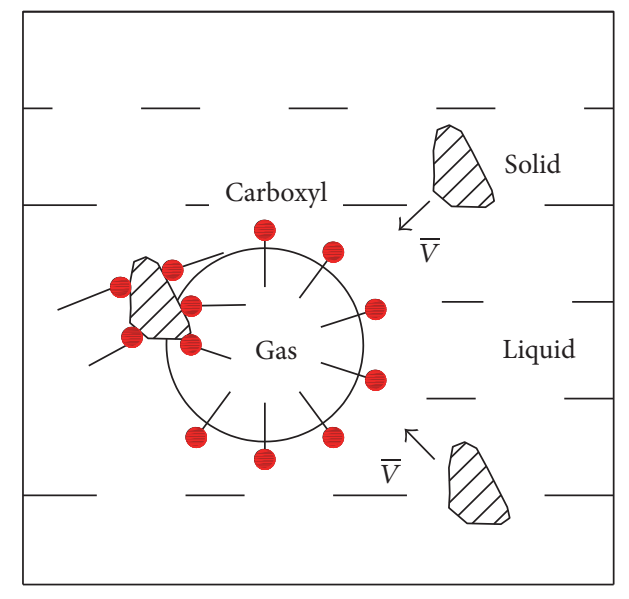

(a)

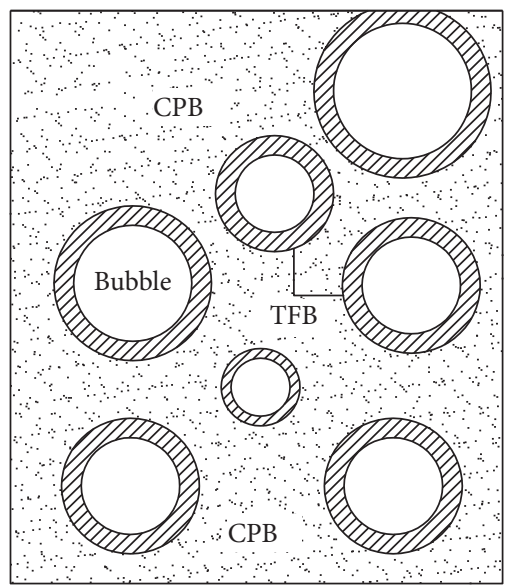

(b)

FIGURE 1: Mechanism of foaming system: (a) foaming reaction process; (b) TFB.

\section{Materials and Methods}

2.1. Materials. Denoting the particle sizes by $D$, the grain diameter of SUT at Sijiaying is shown in Table 1. With $76 \%$ of the content smaller than $0.05 \mathrm{~mm}$ and $3.6 \%$ larger than $0.5 \mathrm{~mm}$, the tailings are classified as superfine with only $0.019 \mathrm{~mm}$ of median grain diameter and a very small permeability coefficient [10]. Owing to the highly oxidized and argillized nature of the ore, the tailings are full of argillaceous minerals such as biotite and chlorite. Particle sizes of mud content in SUT are shown in Table 2. As the content less than $6.5 \mu \mathrm{m}$ exceeds $71 \%$, the prepared CPT shows high viscosity and large resistance loss in long pipeline transportation.

2.2. Sample Preparation. A foaming agent, which is a surfactant, can effectively reduce the surface tension of a liquid and form bubbles with the surrounding air with its double-electron layer arrangement in the liquid film surface [11]. Hydrophilic, carboxyl, and hydrophobic are the main molecular composition of LC-01 foaming agent after being uniformly diluted. The hydrophilic groups trap air molecules nearby, forming a layer of hydrophilic groups neatly arranged at a stable adsorption layer in the periphery of the bubbles. By reducing the surface tension of water, the stability of bubbles can be reliable [12]. The foaming system and TFB are shown in Figure 1.

Under the action of mechanical stirring and jet impingement, cement and SUT are accelerated and move toward the bubble. As important products of cement hydration reaction, $\mathrm{Ca}^{2+}$ and $\mathrm{Mg}^{2+}$ can react with the carboxyl groups of foaming agent, which will form protective shells around the bubble and make it more stable [13].

High-speed mixing and compressed air method are the currently used foaming technologies. Since the compressed air foaming method is more efficient, the obtained foams are more uniform and stable. The HT-10 automatic foaming machine is used for laboratory tests to produce high, uniform, and stable foam.

2.3. Rheological Model. Solid-liquid-gas TFB was prepared with uniform and stable foams, cement, unclassified tailings and water, and so forth at a certain mixing ratio, mixing and stirring uniformly. Considering the composition ratio of each phase may have great impact on the rheological model, the TFB pipeline transportation system is more complex than traditional solid-liquid two-phase CPB [14].

Non-Newtonian fluids include Bingham plastic fluid, pseudoplastic fluid, and expansion fluid, depending on different rheological properties [15]. In previous studies, CPB was simplified as a Bingham plastic fluid, whose flow properties were time-independent, and the existing empirical formulas for calculating the hydraulic gradient of a paste-like flow were derived based on the time-invariant Bingham model [16]. However, an increasing number of studies have shown that the rheological characteristics of TFB are consistent with those of a pseudoplastic fluid, and the existing empirical formulas are optimal for calculating the error and for small 


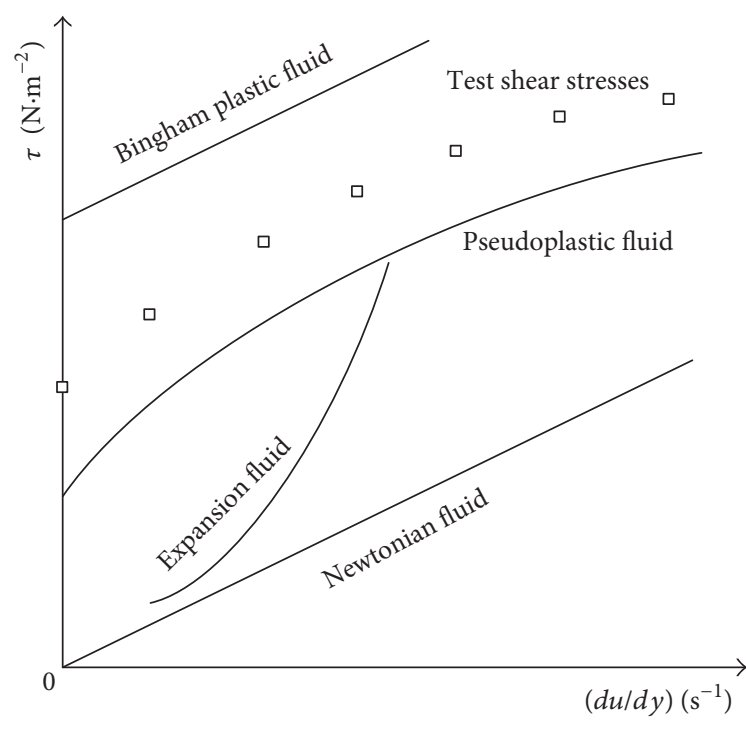

FIGURE 2: Rheological models of different fluid types.

applications [17]. To validate the rheological model of TFB, shear stresses with different shear rates were tested, as shown in Figure 2.

The results show that the behavior of TFB is consistent with that of a pseudoplastic fluid, and the Herschel-Bulkley model is more applicable to TFB. The constitutive equation of the Herschel-Bulkley model is commonly written as follows:

$$
\tau=\tau_{0}+\eta \dot{\gamma}^{n}
$$

where $\tau$ is the shear stress in $\mathrm{Pa}$; $\tau_{0}$ is the yield stress in $\mathrm{Pa} ; \eta$ is the apparent viscosity in Pa.s; and $n$ is the flow index, $n<1$.

2.4. Laboratory Shear Tests. The HAAKE VT550 rotary viscometer was used for laboratory shear tests. The immersion sensor, whose cross-shaped rotor overcomes the slip effect of the PLTS, has higher measurement accuracy than a traditional coaxial cylinder. The control software, which is installed in the computer, can easily handle and record slight changes in the rheological parameters during shear tests.

After a series of preliminary combination experiments, TFB with cement-sand ratio of $1: 8$ and mass concentration of $70 \%$ was found to exhibit good strength and rheology performance, while the bubble ratio was initially selected from $10 \%$ to $20 \%$. The TFB of Sijiaying with different bubble ratio was prepared in advance, rapidly stirred using an electric mixer, and kept stagnant for about $5 \mathrm{~min}$. Subsequently, $900 \mathrm{~g}$ of TFB was taken in a $500 \mathrm{~mL}$ beaker and placed under the viscometer. Laboratory shear tests were conducted to measure the apparent viscosity and shear stress of TFB in five groups.

\section{Results and Discussion}

3.1. Test Results. The variation in the shear stress and apparent viscosity with the shear rate are shown in Figure 3. The shear rate is set as $20 \mathrm{~s}^{-1}, 35 \mathrm{~s}^{-1}, 50 \mathrm{~s}^{-1}, 65 \mathrm{~s}^{-1}$, and $80 \mathrm{~s}^{-1}$.
It was further verified that TFB is consistent with that of a pseudoplastic fluid by the laboratory shear tests. When the bubble ratio was zero, the TFB was consistent with traditional $\mathrm{CPB}$. Following the increase of shear rate, the shear stress of TFB increases while the apparent viscosity decreases gradually. When the shear rate exceeds $50 \mathrm{r} / \mathrm{s}$, the internal foam structure of TFB is gradually destroyed, and the shear stress and apparent viscosity tend to stabilize. With the increase of bubble ratio, the initial yield stress, shear stress, and apparent viscosity of TFB gradually decrease. The greater the bubble ratio, the lower the apparent viscosity and the higher the shear stress.

3.2. Mechanism Analysis. In order to explain the action mechanism of TFB, a series of small pipeline transportation tests was conducted and the change process of bubble in pipeline transportation was shown in Figure 4. For traditional $\mathrm{CPB}$, solid-liquid high-mud SUT is the turbulent viscous sublayer which will produce big resistance loss under the continuous shearing force provided by the pipe wall. After bubbles are incorporated into TFB, the bubbles are big and unordered before pipeline transportation. Under the action of gravity, the big bubbles will rise to the surface of pipe wall and space evenly. Under the continuous shearing force provided by the pipe wall, the big bubbles will split into small bubbles and form new turbulent viscous sublayer in place of high-mud SUT. As a result, the resistance loss of TFB will be decrease and the pipeline transportation efficiency will be improved.

3.3. Pipeline Transportation Simulation. In order to evaluate the pipeline transportation performance of TFB in Sijiaying, Fluent software is used to simulate the process of pipeline transportation. After being uniformly mixed and stirred, TFB can be considered as a homogeneous full-pipe flow and treated as an incompressible steady flow [18]. The Euler method was selected as the slurry model, the inlet boundary of the vertical duct as velocity inlet, and the outlet boundary of the horizontal duct as outflow [19].

TFB with different bubble ratios were filled through a filling pipeline with a diameter of $100 \mathrm{~mm}$ and a filling time of 4.0. The wall roughness height was set as $0.0325 \mathrm{~mm}$, wall roughness coefficient as 0.12 , and vertical acceleration of gravity as $9.8 \mathrm{~m} / \mathrm{s}^{2}$. The residuals were monitored to determine the calculation convergence. Although the oscillation occurs in the initial stage, the monitoring curve of each variable tends to level after 926 iterations, so the simulation results are relatively reliable. The results of the Fluent numerical simulation are listed in Table 3 . The flow velocity variation is shown in Figure 5.

Assuming the pressure at the horizontal-drilling elbow as 0 , the outlet pressure of TFB with $20 \%$ bubble ratio is $-3.21 \mathrm{MPa}$, about $30 \%$ lower than that of traditional $\mathrm{CPB}$. The elbow flow velocity range and the flow velocity of TFB with $20 \%$ bubble ratio are $2.19 \sim 3.02 \mathrm{~m} / \mathrm{s}$ and $1.87 \mathrm{~m} / \mathrm{s}$, both of which are significantly higher than those of CPB. The pipeline resistance loss of TFB calculated by Fluent software is $4.48 \mathrm{MPa}$, which is about $29 \%$ lower than that of CPB. 


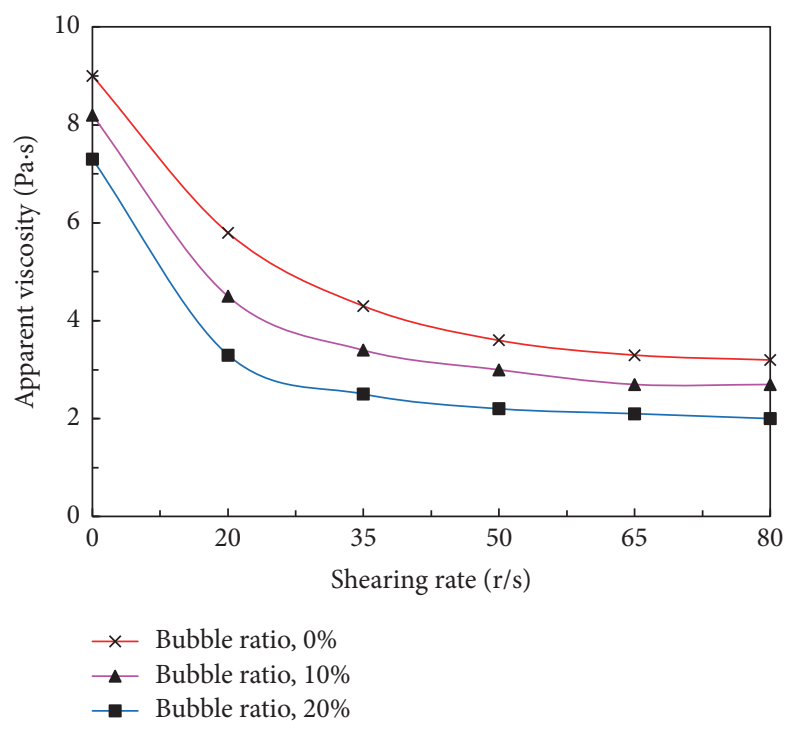

(a)

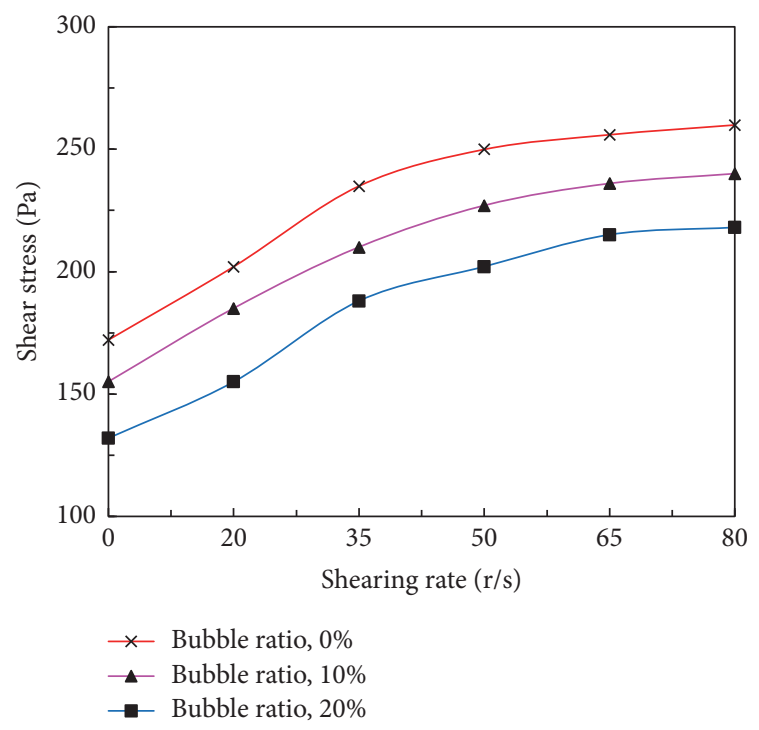

(b)

FIGURE 3: Influence of bubble ratio on the rheological parameters of TFB.

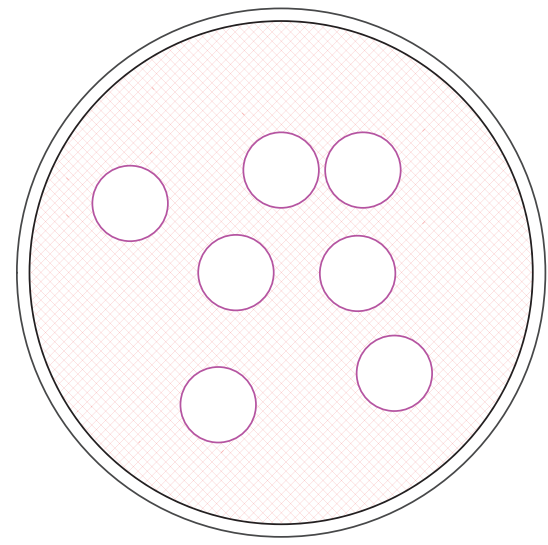

(a)

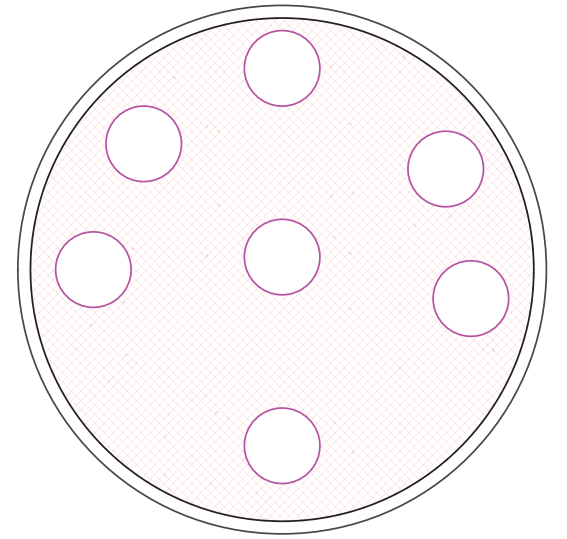

(b)

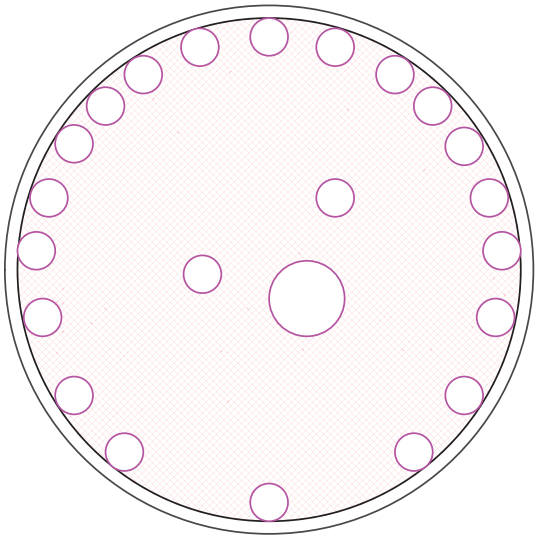

(c)

FIGURE 4: Change process of bubble in pipeline transportation: (a) big and unordered bubble before transportation; (b) big and ordered bubble when transportation; (c) small and ordered bubble in transportation.
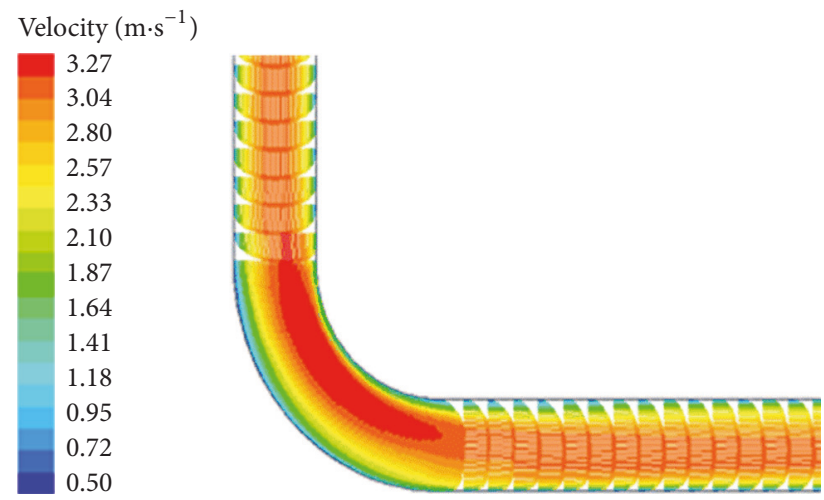

FIgURE 5: Duct velocity profile of TFB at elbow.
3.4. Loop Experiments. During the simulating process of Fluent, it is necessary to adopt certain assumptions and preconditions. Therefore, it is necessary to carry out laboratory loop experiments for further verification. To evaluate the reliability of simulation results by Fluent, a semi-industrial loop test was conducted.

In the loop test, seamless steel ducts with an inner diameter of $100 \mathrm{~mm}$ and wall thickness of $7 \mathrm{~mm}$ are used. The ducts are horizontally arranged and connected via rapid couplers in the system, where the initial pressure and flow velocity are achieved by the use of an industrial filling pump. In the test system, the total pipeline length is about $120 \mathrm{~m}$, and the hydraulic gradients of TFB were calculated by recording the press values of the observation points (see Figure 6). 
TABLE 3: Results of the Fluent numerical simulation.

\begin{tabular}{lcccccc}
\hline $\begin{array}{l}\text { Bubble rate } \\
(\%)\end{array}$ & Flow velocity $\left(\mathrm{m} \cdot \mathrm{s}^{-1}\right)$ & Duct pressure $(\mathrm{kPa})$ & $\begin{array}{c}\text { Outlet velocity } \\
\left(\mathrm{m} \cdot \mathrm{s}^{-1}\right)\end{array}$ & $\begin{array}{c}\text { Outlet } \\
\text { pressure }(\mathrm{MPa})\end{array}$ & $\begin{array}{c}\text { Friction loss } \\
(\mathrm{MPa})\end{array}$ & $\begin{array}{c}28 \mathrm{~d} \text { Strength } \\
(\mathrm{MPa})\end{array}$ \\
\hline 0 & $1.95 \sim 2.68$ & $0.58 \sim 3.20$ & 1.45 & -4.58 & 6.32 & 1.65 \\
10 & $2.15 \sim 2.72$ & $0.75 \sim 3.66$ & 1.62 & -4.05 & 5.89 & 1.62 \\
20 & $2.19 \sim 3.02$ & $0.93 \sim 3.85$ & 1.87 & -3.21 & 4.48 & 1.58 \\
\hline
\end{tabular}

TABLE 4: Comparison of rheological parameters between TFB and CPB.

\begin{tabular}{lccccccc}
\hline \multirow{2}{*}{ Bubble rate (\%) } & \multirow{2}{*}{ Density $\left(\mathrm{kg} \cdot \mathrm{m}^{-3}\right)$} & \multirow{2}{*}{ Bleeding rate (\%) } & \multicolumn{2}{c}{ Strength $(\mathrm{MPa})$} & \multirow{2}{*}{ Consistency $(\mathrm{cm})$} & \multirow{2}{*}{ Slumps $(\mathrm{cm})$} & \multirow{2}{*}{ Viscosity $(\mathrm{Pa} \cdot \mathrm{s})$} \\
\hline 0 & 1940 & 8.33 & 0.75 & 1.66 & 9.5 & 20.2 & 3.25 \\
20 & 1510 & 6.08 & 0.70 & 1.60 & 11.0 & 23.5 & 2.44 \\
\hline
\end{tabular}

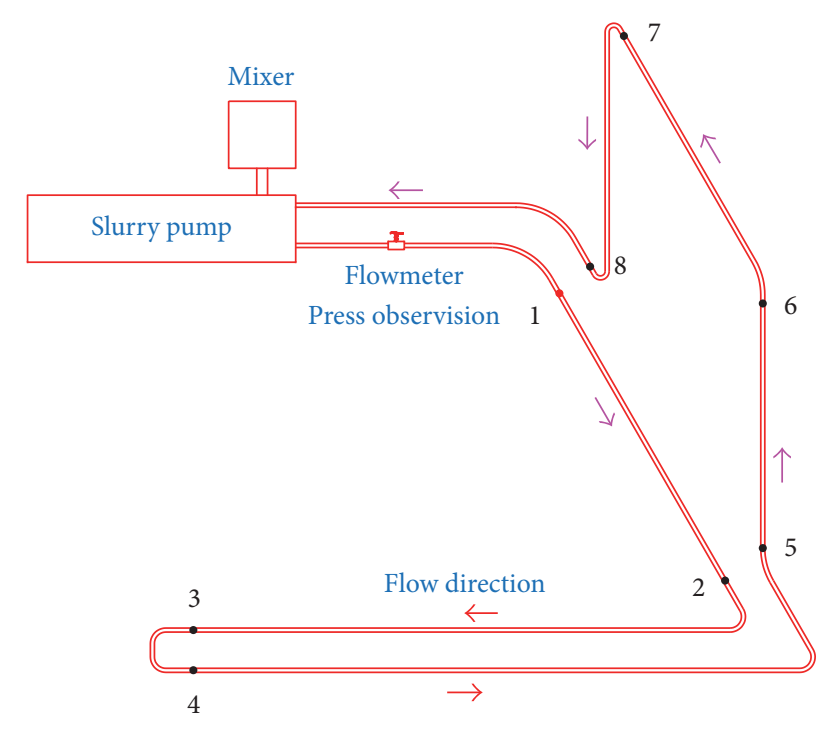

Figure 6: Layout of the loop system.

Both the unclassified tailings slurry with the bubble ratio of $20 \%$ and the bubble-free unclassified tailings slurry are, respectively, put into the loop experiments under conditions with the same inlet pressure. The inlet and outlet pressure distribution of TFB with a bubble ratio of $20 \%$ and CPB are shown in Figures 7 and 8, respectively. The semi-industrial loop test shows that the pressure profiles of TFB and CPB are consistent with the simulation results by Fluent. The calculated hydraulic gradients of TFB are $1.58 \mathrm{MPa}$, about $28 \%$ lower than that of $\mathrm{CPB}$, which also approach the simulation results.

3.5. Application Effects. After a series of repeated experiments, the optimum ratio of TFB of Sijiaying is a cementsand ratio of $1: 8$, mass concentration of $70 \%$, and bubble ratio of $20 \%$. Compared with CPB, the decrease of bleeding rate, viscosity, and resistance loss of TFB is $27 \%, 25 \%$, and $30 \%$, respectively (see Table 4). Therefore, foaming technology is an innovative and feasible solution for high-mud $\mathrm{CPB}$ in reducing viscosity, decreasing resistance loss, and improving pipeline transporting efficiency.

\section{Conclusions}

Foaming technology was introduced into the preparation of TFB in Sijiaying and a series of Fluent simulation and semiindustrial loop test was conducted. The conclusions are made as follows.

(i) As a surfactant, foaming agent, which is made up of hydrophilic, carboxyl, and hydrophobic, can reduce the surface tension of water, react with $\mathrm{Ca}^{2+}$ and $\mathrm{Mg}^{2+}$ of the cement hydration reaction, and form uniform and stable bubbles. After bubbles are incorporated into TFB, small and ordered bubbles will form new turbulent viscous sublayer in place of high-mud SUT, leading to the decrease of resistance loss of TFB and improving the pipeline transportation effectively.

(ii) Both the Fluent simulation and semi-industrial loop test get the approach results. The results show that the outlet pressure, elbow flow velocity range, outlet flow velocity, and pipeline resistance loss of TFB are significantly higher than those of CPB.

(iii) The optimum ratio of TFB of Sijiaying is a cementsand ratio of $1: 8$, mass concentration of $70 \%$, and bubble ratio of $20 \%$. Compared with CPB, the decrease of bleeding rate, viscosity, and resistance loss of TFB is $27 \%, 25 \%$, and $30 \%$, respectively. Therefore, foaming technology is an innovative and feasible solution for high-mud CPB in reducing viscosity, decreasing resistance loss, and improving pipeline transporting efficiency.

\section{Conflicts of Interest}

The authors declare that there are no conflicts of interest regarding the publication of this paper.

\section{Acknowledgments}

This study was supported by a grant from the National Key R\&D Program of China (2017YFC0804605), the Postdoctoral 


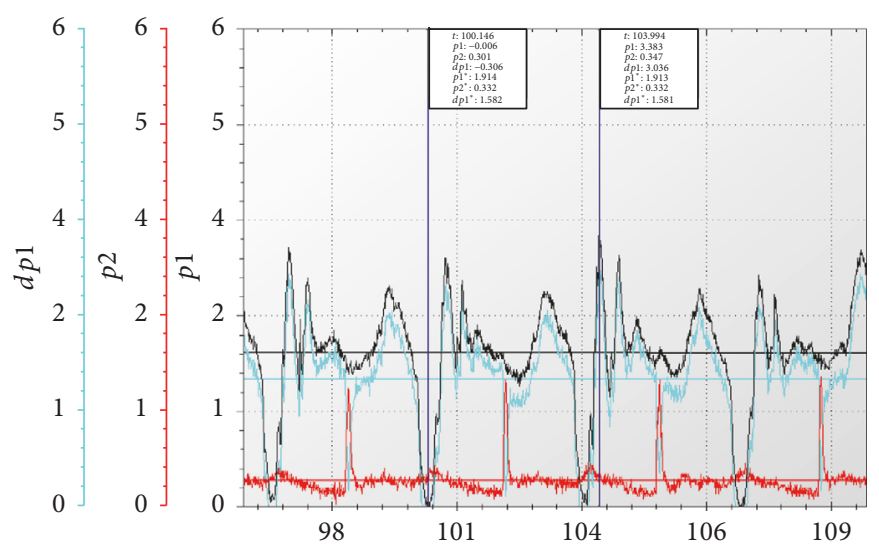

FIgURE 7: The inlet and outlet pressure profile of TFB.

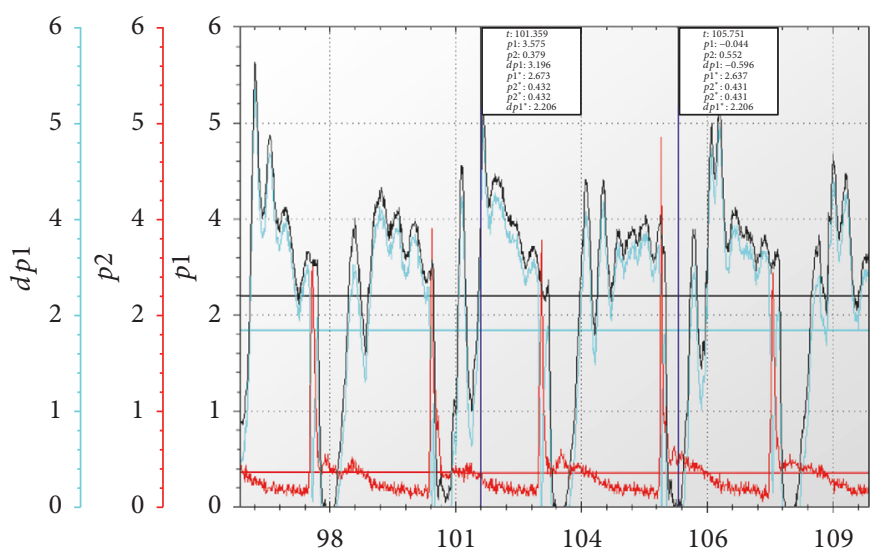

FIGURE 8: The inlet and outlet pressure profile of CPB.

Science Foundation of Central South University (160320002), the project funded by China Postdoctoral Science Foundation (2017M612591), and the Natural Science Foundation of China (51774058).

\section{References}

[1] R.-J. Jewell and A.-B. Fourie, Paste and Thickened Tailings: A Guide- Australian Centre for Geomechanics, ACG, Perth, Australia, 2nd edition, 2006.

[2] S. Li and X.-M. Wang, "Fly-ash-based magnetic coagulant for rapid sedimentation of electronegative slimes and ultrafine tailings," Powder Technology, vol. 303, pp. 20-26, 2016.

[3] J. Qiu, L. Yang, X. Sun, J. Xing, and S. Li, "Strength characteristics and failure mechanism of cemented super-fine unclassified tailings backfill," Minerals, vol. 7, no. 4, 58 pages, 2017.

[4] C.-Y. Xu, T.-C. Sun, J. Kou, Y.-L. Li, X.-L. Mo, and L.-G. Tang, "Mechanism of phosphorus removal in beneficiation of high phosphorous oolitic hematite by direct reduction roasting with dephosphorization agent," Transactions of Nonferrous Metals Society of China, vol. 22, no. 11, pp. 2806-2812, 2012.

[5] A. Kesimal, B. Ercikdi, and E. Yilmaz, "The effect of desliming by sedimentation on paste backfill performance," Minerals Engineering, vol. 16, no. 10, pp. 1009-1011, 2003.
[6] Y. Huang, G. Han, J. Liu, and W. Wang, "A facile disposal of Bayer red mud based on selective flocculation desliming with organic humics," Journal of Hazardous Materials, vol. 301, pp. 46-55, 2016.

[7] F. Cihangir, B. Ercikdi, A. Kesimal, A. Turan, and H. Deveci, "Utilisation of alkali-activated blast furnace slag in paste backfill of high-sulphide mill tailings: effect of binder type and dosage," Minerals Engineering, vol. 30, pp. 33-43, 2012.

[8] X. Tian, Q. Li, Z. Lu, and Z. Wang, "Experimental study of blast mitigation by foamed concrete," International Journal of Protective Structures, vol. 7, no. 2, pp. 179-192, 2016.

[9] S. Xu, F. T. Suorineni, K. Li, and Y. Li, "Evaluation of the strength and ultrasonic properties of foam-cemented paste backfill," International Journal of Mining, Reclamation and Environment, pp. 1-14, 2016.

[10] Y. Zhou, H. Deng, and J. Liu, "Rational utilization of fine unclassified tailings and activated blast furnace slag with high calcium," Minerals, vol. 7, no. 4, article no. 48, 2017.

[11] Z. Zhang, J. L. Provis, A. Reid, and H. Wang, "Mechanical, thermal insulation, thermal resistance and acoustic absorption properties of geopolymer foam concrete," Cement \& Concrete Composites, vol. 62, pp. 97-105, 2015.

[12] H.-S. Lee, M. A. Ismail, Y.-J. Woo, T.-B. Min, and H.-K. Choi, "Fundamental study on the development of structural lightweight concrete by using normal coarse aggregate and foaming agent," Materials, vol. 7, no. 6, pp. 4536-4554, 2014. 
[13] E. Kuzielová, L. Pach, and M. Palou, "Effect of activated foaming agent on the foam concrete properties," Construction and Building Materials, vol. 125, pp. 998-1004, 2016.

[14] R.-P. Chhabra and J.-F. Richardson, Non-Newtonian Flow and Applied Rheology: Engineering Applications, ButterworthHeinemann, Oxford, UK, 2008.

[15] R.-I. Tanner, Engineering Rheology, Oxford University Press, NY, USA, 1986.

[16] X.-M. Wang, J.-W. Zhao, J.-H. Xue, and G.-F. Yu, "Features of pipe transportation of paste-like backfilling in deep mine," Journal of Central South University of Technology, vol. 18, no. 5, pp. 1413-1417, 2011.

[17] Q. Chen, Q. Zhang, X. Wang, C. Xiao, and Q. Hu, "A hydraulic gradient model of paste-like crude tailings backfill slurry transported by a pipeline system," Environmental Earth Sciences, vol. 75, no. 14, article no. 1099, 2016.

[18] D. Wu, M. Fall, and S. J. Cai, "Coupling temperature, cement hydration and rheological behaviour of fresh cemented paste backfill," Minerals Engineering, vol. 42, pp. 76-87, 2013.

[19] K.-P. Zhou, R. Gao, and F. Gao, "Particle flow characteristics and transportation optimization of superfine unclassified backfilling," Minerals, vol. 7, no. 1, article no. 6, 2017. 

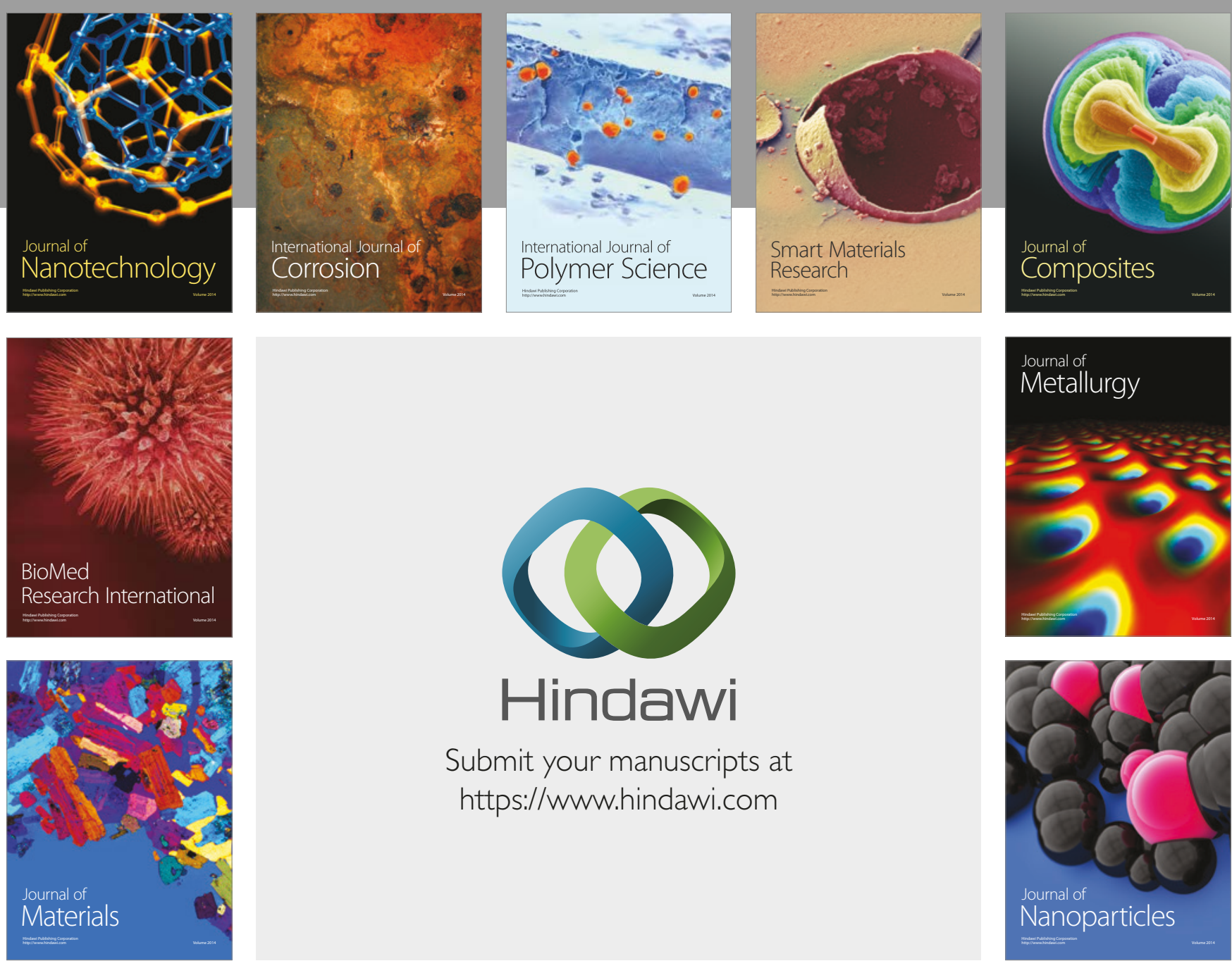

\section{Hindawi}

Submit your manuscripts at

https://www.hindawi.com
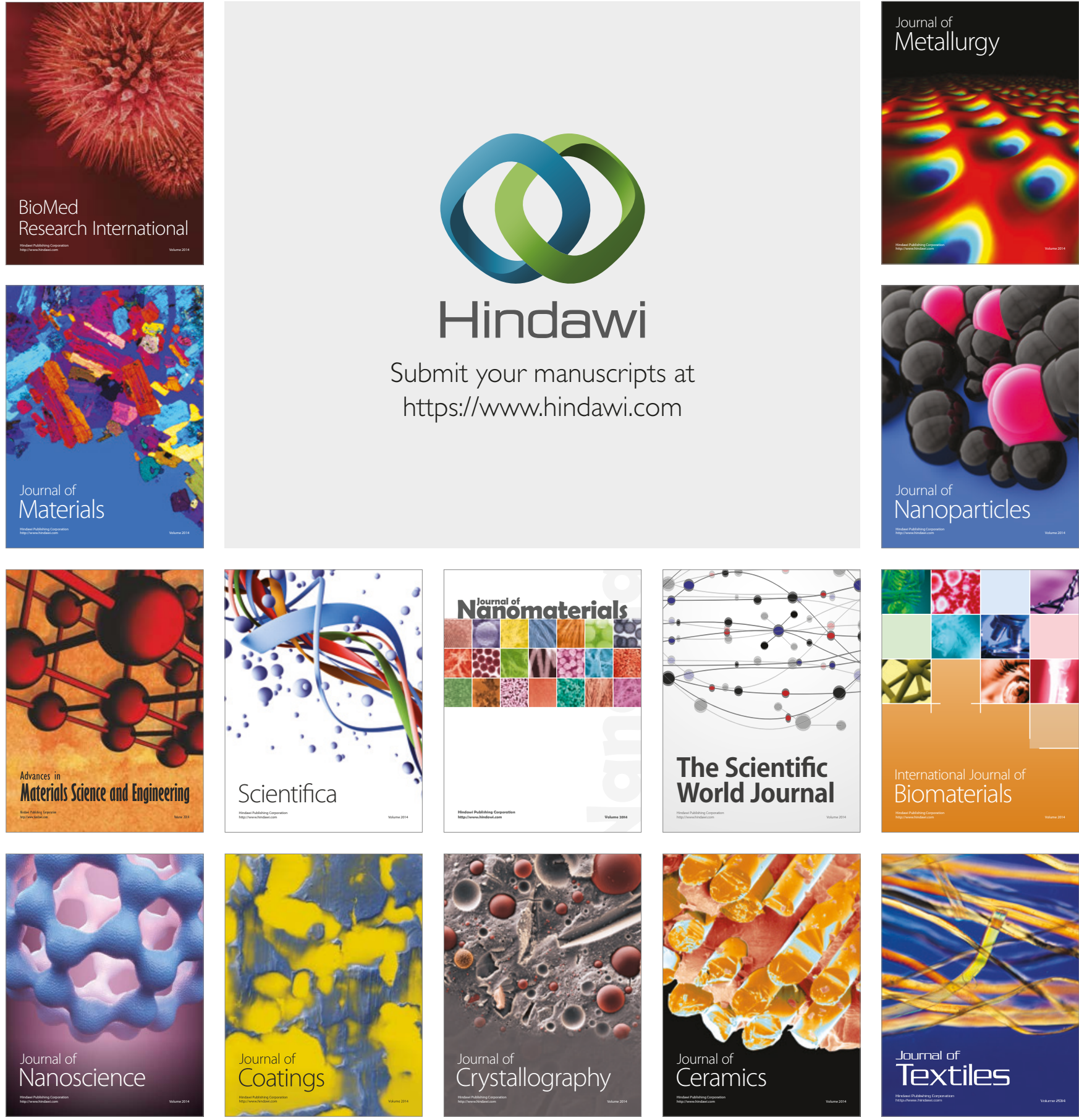

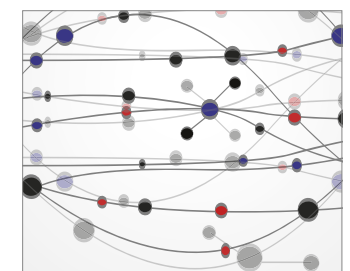

The Scientific World Journal
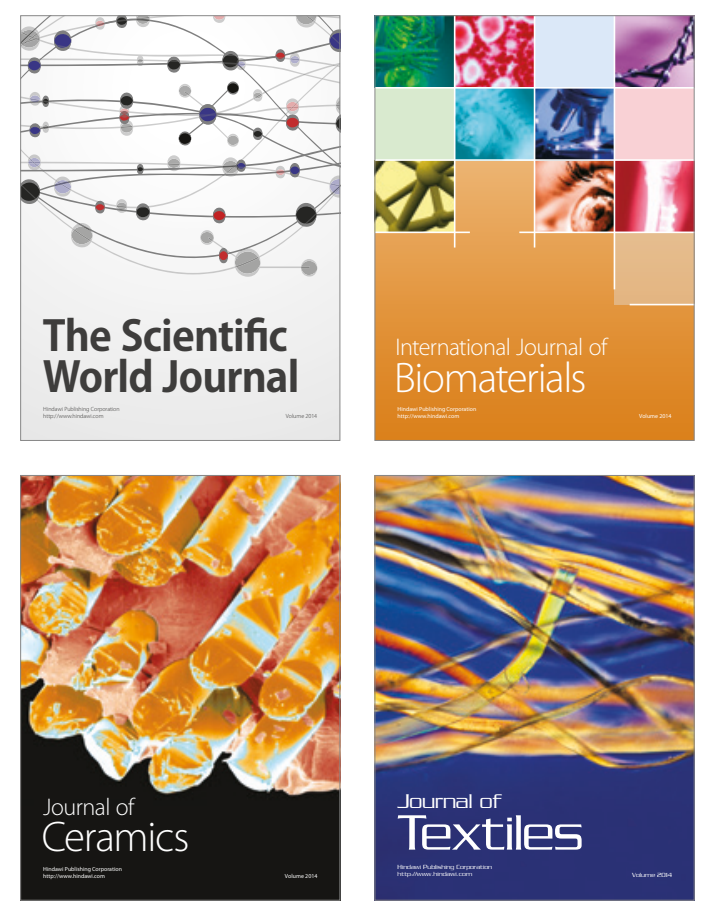